An International Multidisciplinary Double-Blind Peer-reviewed Research Journal

\title{
Literature and its role in shaping the soceity
}

Kakarla Sai Mitravinda, Bachelors in science (Statistics), P S G College of Arts And Science, Bharathiyar University, Coimbatore, TamilNadu, India-641014

\begin{abstract}
Great Literature is simply language charged with meaning to the utmost possible degree". The history of Literature dates back to the dawn of human civilization. The societies were formed by the human beings with objectives of fulfilling the human needs and aspirations. Setting aside which came first- the Literature or society - the aim of the author is to depict the picture of Literature in society and vice versa. Both have remained inseparable from each other, for Literature cannot sustain without society, and likewise the society too cannot be unnoticed in literary pieces in one way or another. This paper is about the importance of Literature and how it influences the minds of people in leading a good life.
\end{abstract}

\section{Introduction:}

Literature is a group of words of art. Most are written, but some are passed by word of mouth. Literature usually means works of poetry and prose that is very well-written. The word Literature comes from the Latin word which literally means learning, Literature and grammar. Even imaginative or creative Literature is considered to be a good Literature.

Before the spread of Literature, oral Literature did not always survive well, though some texts and fragments have persisted. Many texts handed down by oral tradition over several centuries before they were fixed in written form are difficult or impossible to date. August Nitschke sees some fairy tales as literary survivals dating back to ice age and Stone Age narrators. The earliest literary author is a Sumerian priestess known by the name of Enheduanna dates back to 2400 BCE.Certain literary texts such as the Egyptian's Book of Dead and Sumerian's Code of Urkagnia are very old. These old Literature texts have been very helpful in knowing the language, culture and system the people had those days. These texts are foundations of language and Literature that we are having today.

\section{Importance of Literature:}

At the point when we read Literature, we find normal human methods of getting life. We find comparative messages, bits of knowledge, and exercises. We read about firmly related encounters. We likewise find comparative slip-ups. At the point when we read Literature, we likewise find critical contrasts. This permits us to investigate another's message or life, even those isolated from us by time and social boundaries. To peruse Literature is an exercise in perspective. We frequently figure out how unique others are in conditions and way to deal with life, just as experience the different contrasts in what people accept. Literature is brimming with human reactions and responses - in sonnets, expositions, journals, stories, and in the characters of accounts. As we react to and break down these, we can increase a more noteworthy information on the human mind.

Simultaneously, we increase a more noteworthy information on ourselves and our own reactions since we should unavoidably contrast our lives with those in Literature. As we look into, different creators' perspectives as well as our own perspectives and those of others, we extend our feeling of human responses and our own self-reactions. We have the chance of getting further, increasingly mindful individuals. At the point when we do this, we have the open door for finding pride in our locale and culture, for picking up regard for another's, and for learning quietude as we communicate across societies. However being more profound and progressively mindful requires certain ethics, specifically, a feeling of regard and quietude. Great exchange requires confidence, expectation, and love: confidence that correspondence can really happen between individuals; trust that something may happen to our endeavors; and love for our kindred people in the entirety of their assorted variety, unpredictability, and assortment. We don't generally concur with what we read, or we concur to a limited extent. We read Literature to test reality of a message against our perspective. Literature 
An International Multidisciplinary Double-Blind Peer-reviewed Research Journal

can not in itself make us a superior individual, yet it can help us in that mission. Astuteness can be characterized as aptitude in living. By looking at artistic Literatures, their accounts and their messages, we can increment in our comprehension of how to live. We figure out how to perceive what is solid and damaging on the planet, and we are tested with shamefulness and its results. Literature may even provoke us to ask what we will never really end the issues it pictures. Literature offers us the magnificence of words and stories, and all things considered, mirrors the greatness of God present in language, accounts, and the stuff of creation. Literature can engage us. Leland Ryken writes:

"What constitutes a worthwhile use of leisure time? There is no one right answer. . [But] Literature has much to commend it as a leisure activity. In a day of mindless leisure pursuits, Literature stands out by engaging our mind .... It enriches our life by making us aware of the world of human experience and human fears and longings ... We can upgrade the quality of our leisure time by learning to value what is excellent rather than mediocre."

\section{Literature and society:}

What occurs in a general public is reflected in artistic works in some structure. The strict significance of Literature is the specialty of composed work in various structures, for example, verse, plays, stories, composition, fiction and so forth. It might likewise comprise of Literatures dependent on data just as creative mind. A general public is a gathering of individuals identified with one another through their consistent and continuous relations. It is likewise a gathering of likeminded individuals to a great extent represented by their own standards and qualities. Human culture, it is watched, is described by the examples of connection between people who offer societies, conventions, convictions and qualities and so forth. In the event that one glances at the historical backdrop of society, one will find that the idea of various social orders has experienced changes from the Paleolithic time frame to the current period of Information Technology. The people ${ }^{\text {ee }}$ living style, religions, convictions, societies and so on have never remained consistently steady. With the progression of time, attributable to changes occurring in condition and with rise of new advancements, we see that the social orders have not stayed obstinate concerning their standards and qualities, the impressions of which can be found in various types of Literature.

Kalidas , an incredible artist , at any point conceived in Indian history, is first scared of the dubious demeanor of the individuals, yet then argues his own places of perspectives that give us association of the old and the new. In Malavikamitam, his first play, the writer shows his quietude and becomes dubious whether individuals would acknowledge his play. Subsequently, in the start of the play, he argues, Puranamityek Nasadhu sarvam,Nachapikavayamnavmityavadyam "Each old sonnet isn't acceptable on the grounds that it is old; nor is each new sonnet to be accused since it is new; stable pundits, after basic assessment, pick either, the bar must have his judgment, guided by the information on his neighbours."1In different words, everything old isn't awful; nor is everything new awful. There might be something, which may not be very useful in the old, and the new may likewise be acceptable. That what extraordinary men and shrewd individuals state and follow become great during record-breaking. In regard of Literature too we notice that it has surprisingly experienced changes with respect to its topic and style. The subjects of Literature have been changing as they spread various circles of life and society. So has been the situation with the case with the language of Literature too.

Language is one of the apparatuses or mechanisms of communicating thoughts and considerations, both in oral and composed structures. Various social orders have utilized are as yet utilizing various dialects for the satisfaction of people, and societies ${ }^{\text {ee }}$ yearnings. At some point it is seen that numerous charges are marked against Literature just as society. A scholarly composing is restricted on the grounds that a contrary area of society discovers it reflecting convictions and standards against that society. The instances of Salman Rushdiees The Satanic Verses and Taslima Nasrin "es Lazza give declaration to suchcharges. The canvases of Maqbul Fida Hussain were restricted and consumed by an area Indian Hindu society with the charge of discoloring their strict dedication. In the realm of film industry, both in India and abroad, numerous movies have been restricted; there 
An International Multidisciplinary Double-Blind Peer-reviewed Research Journal

has been fights and showings against the movies for wrongly introducing the subjects and utilizing undesired language which seem antagonistic to the sentiments of a segment of society.

\section{Literature is the mirror of society:}

Literature has majorly affected the improvement of society. It has molded civilisations, changed political frameworks and uncovered foul play. Literature gives us an itemized review of human encounters, permitting us to associate on fundamental degrees of want and feeling. In any case, similarly as it has built social orders, the compositions and works of specific creators have corrupted social orders to their most crude structure. The UAE is just 36 years of age. In a nation that is as yet experiencing quick turn of events, the potential effect of Literature is obvious. An informed youth, which grasps the eventual fate of the country, has the ability to impact change.

"The foundation of every state is the education of its youth," said Kevin Nawn, assistant professor of English at the American University in Dubai. "The youth should be educated in the great ideas of not only its own culture and time, but other cultures and times as well."

\section{Are movies making us move away from Literature?}

Numerous understudies ascribed the absence of enthusiasm for Literature to an absence of persistence. Most said that out of their friend network, half of them get a book."It's a bustling world and it's getting much busier with time," said M. Raj, establishment understudy at Middlesex University.We scarcely possess energy for ourselves, how might we have the opportunity to plunk down and peruse? In light of this absence of time and anxiety, understudies look to different types of information and correspondence, something that will rapidly furnish them with the data they need. While a book may take a month to complete, a film could pass on a similar message in only two hours. In any case, what understudies don't see is that these 'convenient solutions' may not be furnishing them with the full and precise message."One of Literature's primary characteristics is that it is not entirely clear," Caesar said. Nonetheless, Caesar said that the fast rise of new innovation would not prompt the disposal of Literature. Individuals won't quit perusing since they're watching films. Both fulfill the requirement for an account. The two rather cover. For instance, perusing a novel and afterward watching the film may help comprehend the understanding better.

\section{Conclusion:}

Literature has the ability to sparkle a light on a general public's convictions and practices. It powers perusers to pose inquiries, start discussions and search for answers, regardless of whether one genuine answer doesn't exist. The topics, characters and exercises in Literature are ones that would all be able to be contrasted with the individuals and occasions perusers find in reality. In that sense, Literature is an impression of society. Therefore, apparently society acts like back up for culture and convention of the individuals it reflects upon and the occupants of a gathering of society share certain likenesses as to, suspicions, convictions, standing, belief, fantasies, religion and so forth. Literature, when joined with culture and different features - both conceptual and cement - of society, not just presents vague subjects like estrangement, digestion and change in the public arena yet in addition mirrors the substantial issues, ,for example, ,chronicled, political and social realities.

\section{References:}

Arjun Dubey,"Literature and society", IOSR Journal Of Humanities And Social Science (IOSR-JHSS) Volume 9, Issue 6 (Mar. - Apr. 2013), PP 84-85

Manali Ismail,Artice,"Literature is the mirror of society", February 24, 2008,Gulf News

Carter,Ronald;Burnon Deidre,"Literary text and language study",Explotation in Language study, Great Britain,1982 
An International Multidisciplinary Double-Blind Peer-reviewed Research Journal

Croft,Kennet,"Reading and word study", Prentice hall,USA,1960

Wellek R and A Warren, “Theory of Literature”,Penguin, 1920 